\title{
Comparative Study of Efficacy of Combination of Valenthamate Bromide \&Buscopan with Drotavarine Hydrochloride on Cervical Dilatation in Active Labour
}

\author{
Dr.I. Naga Prathyusha ${ }^{1}$,Dr.B.ShilpaShivanna ${ }^{2}$, Dr.K.Subbappa ${ }^{3}$, Dr.N. Gopal ${ }^{4}$ \\ 1 Junior resident, Department of $O B G$, Adichunchanagiri Institute of Medical Sciences, B.G.Nagara,MandyaDist \\ 2 AssociateProfessor, Department of $O B G$,Adichunchanagiri Institute of Medical Sciences, B.G.Nagara,Mandyadist \\ 3 Senior resident, Department of $O B G$, Adichunchanagiri Institute of Medical Sciences, B.G.Nagara,Mandyadist \\ 4 Professor, Department of OBG, Adichunchanagiri Institute of Medical Sciences, B.G.Nagara,Mandyadist
}

\begin{abstract}
Prolonged labour contributes to increased perinatal and maternal morbidity.Various drugs have been tried to hasten the cervical dilatation, so that problems and hazards of prolonged labourare minimized. Aim of the study is1)To compare the efficacy of combination of valenthemate bromideandbuscopanvsdrotavarine hydrochloride on cervical dilatation in active labour.2)To compare the duration of active phase of labour, 3) To see for associated complications like cervical tears. 100 women with full term singleton pregnancy were included in the studywith gestational age 37-42 weeks with, cephalic presentation in active labour. Cases were divided into 2 groups, group A 50 cases- labour accelerated by drotine and group B 50 cases- labour accelerated by combination of epidosine \&buscopan.Mean duration of active phase of $1^{\text {st }}$ stage of labour was 3 hrs 11 min indrotinegroup and 4 hrs 16 min inepidosine\&buscopan group. Mean rate of cervical dilatation according to active phase of $1^{\text {st }}$ stage was $1.97 \mathrm{~cm} / \mathrm{hr}$ in drotine group and $1.45 \mathrm{~cm} / \mathrm{hr}$ inepidosine + buscopan group. The difference between the two groups is significant $(p<0.01)$, thus it is concluded that drotine hastened the rate of cervical dilatation.
\end{abstract}

Key Words: Cervical dilatation, Active phase of $I^{\text {st }}$ stage,Drotavarine hydrochloride, Epidosine, Buscopan.

\section{Introduction :}

Labour is a multi-factorial process that involves myometrial contraction, cervical ripening and dilatation $\&$ then expulsion of fetus and placenta. $1^{\text {st }}$ stage of labour in a primigravida lasts for 12-16 hrs and in parous women usually 6-8 hrs. There is a general consensus of opinion to classify labour lasting over $24 \mathrm{hrs}$ as prolonged labour. The progress of labour is assessed by progressive dilatation and effacement of cervix and descent of presenting part [1-4].

Cervical dilatation is one of the important factors which determines the duration of labour and is the resultant of all driving forces of uterine contraction acting against passive tissue resistance [1,5]..Prolonged labour can lead to increased maternal and neonatal mortality and morbidity due to increased risks of maternal exhaustion, postpartum haemorrhage, sepsis, fetal distress, asphyxia which require early detection and appropriate clinical response. There are many causative factors associated with prolonged dilatation stage of labour, such as maternal age, induction of labour, PROM , initial state of cervix, rate of cervical dilatation, intensity of uterine contractions, presentation, CPD, constitutional characteristics, parity of parturient and high levels of maternal stress hormone [2,3].

Active management of labour is a part and parcel of modern obstetrics. There are various mechanical and pharmacological methods by which the cervical dilatation can be facilitated e.g., sweeping of membranes and stretching of cervix which causes local release of PG'S resulting in reduction in the need for formal induction of labour, amniotomy, antispasmodics, belladonna alkaloids etc. [1-5]. The drug to be used during labor should fulfil the following criteria: It should not have any depressant action on the course of labor , It should not have any untoward effect on the fetus, It should not have any ill effect on the mother.

Drotavarine, an isoquinolone derivative is a highly potent spasmolytic agent which acts specifically on spastic sites and corrects the c AMP and calcium balance relieving smooth muscle spasm but devoid of anticholinergic effect. This inhibitory action is detected only in lower uterine segment during labour, since muscle fibres in upper uterine segment are strongly affected by contractile effect of oxytocin. Epidosine has neurotropic andmusculotropic actions, resulting in relaxation of cervical musculature leading to quick dilatation of cervix and shortened labour.Buscopan is a derivative of hyoscine, antispasmodic, acts by inhibiting transmission in the abdominal and pelvic parasympathetic ganglia, relieving spasm in the smooth muscles of cervico-uterine plexus and thus aiding cervical dilatation [6-8].These drugs do not affect uterine contractions, rather due to better coordination between uterine contractions and cervical dilatation, they are increased. It has pain relieving effects also due to parasympatholytic action, thus used for both labour acceleration and analgesia $[8,9]$. 


\section{Materials\& Methods :}

100 women with singleton term pregnancy, 37-42 weeks, with cephalic presentation in active phase of labour with cervical dilatation 3-4 cm, 60-80\% cervical effacement who were admitted to labour room of department of OBG, Sri Adichunchanagiri institute of medical sciences, BG Nagara, Mandya district were included in this prospective study. This study was conducted from june 2013 till june 2014, i.e., for a duration of 1 year. EXCLUSION CRITERIA includes Scarred uterus, fetal demise, multiple pregnancy, malpresentations, epidural analgesia, antepartum haemorrhage, prolonged PROM.

GROUP A :Inj . Drotine $40 \mathrm{mg}$ IV at the start of the study \& repeated every $2 \mathrm{hr}$ upto a max of 3 doses.

GROUP B :Inj. Epidosine( $1 \mathrm{amp}$ ) + InjBuscopan ( $1 \mathrm{amp}$ ) IV at $1 / 2 \mathrm{hr}$ interval of 3 doses

\section{Results :}

3.1.TABLE 1 : Comparison of age and period of gestation

\begin{tabular}{|l|l|l|l|}
\hline VARIABLE & GROUP A & GROUP B & pVALUE \\
\hline AGE & 23 YEARS & 23 YEARS & $>0.05$ \\
\hline GESTATIONAL AGE & 39 WEEKS & 38 WEEKS 4 DAYS & $>0.05$ \\
\hline
\end{tabular}

3.2.TABLE 2 : Comparison of duration of active phase of $1^{\text {st }}$ stage of labour

\begin{tabular}{|l|l|}
\hline STUDY & DURATION \\
\hline Sharma et al with epidosine & $3 \mathrm{hrs} 20 \mathrm{~min}$ \\
\hline Pakhe et al with buscopan & $3 \mathrm{hrs} 46 \mathrm{~min}$ \\
\hline Aziz et al with drotine & $2 \mathrm{hrs} 36 \mathrm{~min}$ \\
\hline Present study with group A & $3 \mathrm{hrs} 11 \mathrm{~min}$ \\
\hline Present study with group B & $4 \mathrm{hrs} 16 \mathrm{~min}$ \\
\hline
\end{tabular}

3.3.TABLE 3 : Comparison of rate of cervical dilatation

\begin{tabular}{|l|l|}
\hline STUDY & RATE OF CERVICAL DILATATION \\
\hline Sharma et al with epidosine & $1.86 \mathrm{~cm} / \mathrm{hr}$ \\
\hline Pakhe et al with buscopan & $1.59 \mathrm{~cm} / \mathrm{hr}$ \\
\hline Aziz et al with drotine & $1.90 \mathrm{~cm} / \mathrm{hr}$ \\
\hline Present study with group A & $1.97 \mathrm{~cm} / \mathrm{hr}$ \\
\hline Present study with group B & $1.45 \mathrm{~cm} / \mathrm{hr}$ \\
\hline
\end{tabular}

3.4TABLE 4 :Comparison of incidence of cervical tears

\begin{tabular}{|l|l|}
\hline GROUP & INCIDENCE OF CERVICAL TEARS \\
\hline DROTINE GROUP & 2 ( UNILATERAL $)$ \\
\hline EPIDOSINE + BUSCOPAN GROUP & 0 \\
\hline
\end{tabular}

\section{Discussion :}

Active management of labour has gone a long way in decreasing maternal morbidity and perinatal morbidity and mortality. Hence relieving the pain or shortening the duration of labor will have a significant beneficial effect on mother and fetus, inturn the obstetrician.

The mean age, period of gestation in drotine group were 23 years \& 39 weeks, while in epidosine + buscopan group are 23 years \& 38 weeks 4 days respectively. Both primigravidae and multigravidae were equal in no. in both the groups. The difference was insignificant \& both the groups were comparable for the study in relation to age \& period of gestation. ( TABLE 1 ). Mean duration of active phase of $1^{\text {st }}$ stage of labour was $3 \mathrm{hrs}$ $11 \mathrm{~min}$ in drotine group \& $4 \mathrm{hrs} 16 \mathrm{~min}$ in epidosine + buscopangroup. The difference between the two groups is statistically significant ( $\mathrm{p}<0.01$ ) (TABLE 2), which infers that drotine shortens the duration of active phase of first stage of labour more effectively than epidosine + buscopan which corresponds with Aziz et al.

The duration of $2^{\text {nd }}$ and $3^{\text {rd }}$ stage were also shortened in drotine group compared to group B. It was also concluded that epidosine and buscopan group had increased effect when given after $6 \mathrm{~cm}$ dilatation, and also there was an increase in the effacement of cervix compared to drotine group. Mean rate of cervical dilatation according to active phase of first stage was $1.97 \mathrm{~cm} / \mathrm{hr}$ in drotine group $\& 1.45 \mathrm{~cm} / \mathrm{hr}$ in epidosine +buscopan group. Again the difference between the two groups is statistically significant ( $p<0.01)$, (TABLE 3).Suggests that drotine hastened the rate of cervical dilatation which is in par with Sharma et al, Pakhe et al and Aziz et al.

The incidence of cervical tears is only 2 out of 30 patients in drotinegroup, which had only unilateral tears, that necessitated only suturing, and none of them included tear upto internal os. No patient required blood transfusion because of cervical tear as depicted in TABLE 4.There was no effect on maternal pulse and blood pressure. There was no adverse neonatal outcome in terms of Apgar score and NICU admissions in both the groups. 


\section{Conclusion :}

Active management is part and parcel of modern obstetrics by decreasing the maternal morbidity and perinatal morbidity and mortality, as evidenced in our study where Drotine scores over epidosine or buscopan alone or in combination to shorten the duration of all stages of labour, more so the first stage of labour and also was more beneficial in primis than multiparas. Whereas as combination of epidosine and buscopan was more effective when given after $6 \mathrm{~cm}$ dilatation with an added effect on improvement of effacement which was not seen in drotine group. All the patients responded well to drotine, and the duration of laborwas considerably shortened. All these drugs were found not to have any effect on the intensity, duration or frequency of uterine contractions with no associated complications for either mother or the fetus. Hence it is safe to use these in labour for active management.

\section{References}

[1]. Kaur s, Bajwa SK, Kaur P, Bhupal S. To compare the effect of camylofindihydrochloride with combination of valenthamate bromide and hyoscine butyl N-bromide on cervical dilatation. J ClinDiagn Res. Sep 2013;7(9):1897-1899.

[2]. Maria aziz. Comparative study of tramadol hydrochloride and drotavarine hydrochloride on cervical dilatation in active labor. International journal of scientific and technology research. Apr 2014; 3(4): 338-347.

[3]. Dencker A, Berg M, Bergvist L, Ladfors L, Thorsen LS, Lilja H. Early versus delayed oxytocin augmentation in nulliparous women with prolonged labour- a randomized controlled trial. BJOJ: an international journal of obstetrics and gynaecology 2009; 116:530-6.

[4]. Cunningham G,Gant NF, Leveno KJ, et al. Parturition. Williams obstetrics. $\left(23^{\text {rd }}\right.$ edition ) 2009:136-60.

[5]. Caughey AB, Sundaram V, Kaimal AJ, et al. maternal and neonatal outcomes of elective induction of labor. Evid Rep Technol Assess. 2009; 176:1-257.

[6]. Aggarwal P, Zutshi V, Batra S. Role of hyoscine N- butyl bromide as labor analgesic. Indian J Med Sci 2008; 62: 179-84.

[7]. Buscopan. Mumbai : German remedies, division of Ingelheim, Germany: BoehringerIngelheim limited. 2005.

[8]. Baracho HM, Kamat JR, Kunalhekar, JarobI.Buscopan in acceleration of labor. J ObstetGynecolInd 1984; 34: 509-12.

[9]. Sharma JB, Pundir P, Kumar A, Murthy NS. To compare the efficiency and safety of drotavarine hydrochloride and valenthamate bromide in shortening the duration of labor. Int J Gynaecol Obstet. 2001 Sep; 74(3): 255-60. 